\title{
BREAKWATERS UNDER CONSTRUCTION EXPOSED TO OBLIQUE WAVES
}

\author{
P.H.M. Mulders ${ }^{1}$ and H.J. Verhagen ${ }^{2}$
}

\begin{abstract}
A new series of physical model tests were conducted to analyse the behaviour of a breakwater core when it becomes exposed to wave attack. The emphasis of this research was on the measured influence of a wide stone grading on both the deformation of a breakwater trunk and the occurring longshore transport. This behaviour was investigated for both head-on and oblique waves using two different wave loads. The findings were compared to the currently available formulas and the validity of these formulas for the tested range of parameters was (re)checked. In general a clear distinction was found in the processes between tests with narrow grading and wide grading. It turned out that both the parameters describing the two-dimensional deformation and the longshore transport show an increase for wider grading.
\end{abstract}

Keywords: rubble-mound breakwater; core; grading; physical model test; two-dimensional deformation; stone displacement; longshore transport

\section{INTRODUCTION}

During the construction of breakwaters contractors often encounter undesired reshaping of exposed core material. This reshaping is comparable to the deformation process of berm breakwaters in which the outer profile reshapes into a more stable s-curve. In the case of oblique waves this deformation is enhanced by a longshore transport of stones leading to even more loss of material and damage.

Throughout the years few formulas were derived for both processes which describe the behaviour of berm breakwaters as well as gravel beaches reasonably well. These formulas however turned out to be inadequate when it comes to describing the behaviour of core material. In particular the influence of the wide grading of quarry run, commonly used as core material, is to a large extent unknown and generally not described in the available relations.

\section{BACKGROUND OF RESEARCH}

\section{Profile parameters equilibrium profile}

According to (Van der Meer 1988) the deformed equilibrium profile of a dynamically stable slope can be described by a number of profile parameters characterising three points:

1. Local origin, at the intersection of the profile and the still water level.

2. Crest point, defined as the upper point of the beach crest.

3. Step point, which is the transition from the gentle sloping part to the steep part.

From the results of the accompanying model tests it turned out that all these profile parameters are related to $\mathrm{H}_{0} \mathrm{~T}_{0}$, the dimensionless combined wave height-wave period parameter, or $\mathrm{s}_{\mathrm{m}}$, the fictitious wave steepness:

$$
\begin{aligned}
& H_{0} T_{0}=H_{s} / \Delta D_{n 50} * \sqrt{g / D_{n 50}} T_{m} \\
& s_{m}=H_{s} / L_{0}=2 \pi H_{s} / g T_{m}^{2}
\end{aligned}
$$

In (Van der Meer 1992) the relations regarding the profile parameters were expanded to make better predictions of the profile deformation of berm breakwaters:

-Crest height $\mathrm{h}_{\mathrm{c}}[\mathrm{m}]$ :

$$
H_{0} T_{0}=33\left(h_{c} / D_{n 50} N^{0.15}\right)^{1.3}+30 \cot \alpha_{1}-30 ; \quad H_{0} T_{0}<900
$$

$\bullet$ Crest length $1_{\mathrm{c}}[\mathrm{m}]$ :

$$
H_{0} T_{0}=\left(3 \cot \alpha_{1}+25\right) l_{c} / D_{n 50} N^{0.12}
$$

-Step height $\mathrm{h}_{\mathrm{s}}[\mathrm{m}]$ :

$$
H_{0} T_{0}=27\left(h_{s} / D_{n 50} N^{0.07}\right)^{1.3}+125 \cot \alpha_{2}-475 ; \quad H_{0} T_{0}<300 \cot \alpha_{2}
$$

\footnotetext{
${ }_{1}^{1}$ ArcelorMittal Projects Europe, P.O. Box 52, 4793 ZH Fijnaart, The Netherlands

${ }^{2}$ Faculty of Civil Engineering and Geosciences, Delft University of Technology, P.O. Box 5048, 2600 GA Delft, The Netherlands
} 
-Step length $1_{\mathrm{s}}[\mathrm{m}]$ :

$$
H_{0} T_{0}=2.6\left(l_{s} / D_{n 50} N^{0.07}\right)+70 \cot \alpha_{2}-210
$$

In these relations $\mathrm{N}$ is number of waves and $\alpha_{1}$ and $\alpha_{2}$ are two different equivalent initial slope angles. To take into account oblique wave attack a reduction factor $\cos \psi$ was found for all length and height parameters except the crest length $1_{c}$.

Later on Merli adjusted the relations, found by Van der Meer, for head-on waves in (Merli 2009) using curve-fitting to take into account the influence of stone grading. Seven parameters were defined directly related to the parameters of Van der Meer as is given in Fig. 1. The local origin is defined as the intersection between the reshaped profile and the mean water level.

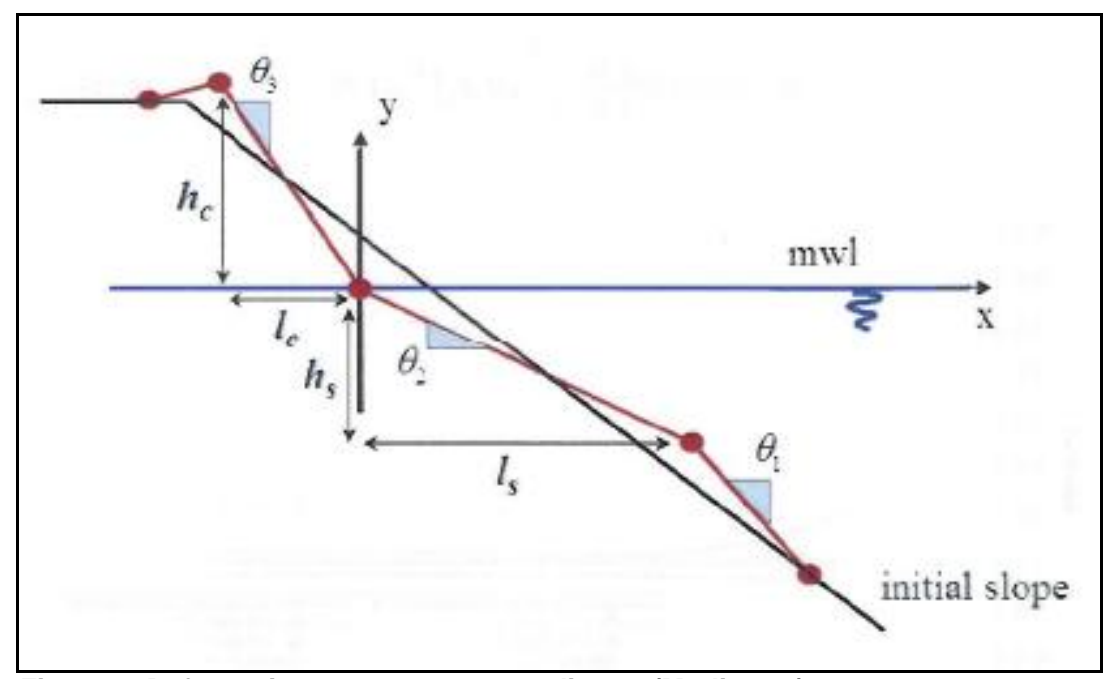

Figure 1: Deformation parameters according to (Merli 2009)

For three of these parameters a clear relation was derived regarding the stone grading ' $\mathrm{f}_{\mathrm{g}}$. The remaining parameters can still be derived according to (Van der Meer 1992):

$$
f_{g}=\frac{D_{n 85}}{D_{n 15}}
$$

$\bullet$ Crest length $1_{\mathrm{c}}[\mathrm{m}]$ :

$$
\left(H_{0} T_{0}-183\right) \cot \alpha_{1}=139\left(l_{c} / D_{n 50} N^{0.12}\right) f_{g}^{-0.29}-667
$$

-Step length $1_{\mathrm{s}}[\mathrm{m}]$ :

$$
H_{0} T_{0}=1.66\left(l_{s} / D_{n 50} N^{0.07}\right)^{1.3} f_{g}^{-0.15}+29.1 \cot \alpha_{2}-9.38
$$

-Slope line connecting local origin and crest $\theta_{3}\left[^{\circ}\right]$

$$
\theta_{3}^{-1}=0.00023 f_{g}^{1.58}\left(H_{0} T_{0}\right)^{0.84}+1.50
$$

\section{Crest recession}

To guarantee the protection of the underlying structure, another parameter called the recession length, Rec, was defined. Through time three different relations were derived for head-on waves, all describing the effect of stone grading in a totally different way. Hall and Kao tested in the range for grading of $1.35<\mathrm{f}_{\mathrm{g}}<5.4$ and found an inverted quadratic relation. According to (Hall and Kao 1991) narrowly graded stones are less prone to reshaping than wider graded stones. For the wider gradings the smaller stones will fill the voids between the larger stones, resulting in a lower permeability. This leads to a decrease in energy dissipation and consequently an increase in erosion volume and berm recession. For even wider gradings ( $f_{g}>3$ ), the effect of very large stones starts to dominate the effect of the voids leading to a decrease in reshaping and Rec. For the range of $1.3<\mathrm{f}_{\mathrm{g}}<1.8$ a totally different quadratic relation was derived in (Pianc Marcom 2003) by Menze and Tørum and Krogh.

The third and last relation was derived by (Merli 2009) who found a linear relation for Rec regarding the stone grading including validity for even wider gradings:

$$
\frac{R e c}{D_{n 50}}=0.218 H_{0} T_{0}+1.62 \frac{D_{n 85}}{D_{n 15}}+105 \tan \alpha-91.5
$$




\section{Longshore transport}

For statically stable breakwaters longshore transport is already accounted for as damage. This is not the case for dynamically stable structures. When the waves come in at an angle, stones may be transported for some distance along the breakwater. Sections will then erode causing a deficit of armour stones and therefore damage to the profile. Equilibrium in the form of a stable S-shape is no longer possible.

(Van der Meer and Veldman 1992) tested already developed profiles of berm breakwaters under angles of $25^{\circ}$ and $50^{\circ}$ and concluded that the longshore transport for large angles of wave attack, like $50^{\circ}$, is much smaller than for $15^{\circ}$ and $30^{\circ}$. They adjusted the existing probabilistic approach and came up with the following formula, valid for $\mathrm{H}_{0}<10$ and $15^{\circ}-35^{\circ}$ :

$$
\begin{array}{ll}
S_{N}(x)=0 & H_{0} T_{0}<105 \\
S_{N}(x)=0.00005\left(H_{0} T_{0}-105\right)^{2} & H_{0} T_{0}>105
\end{array}
$$

In this formula the stone transport rate, $\mathrm{S}_{\mathrm{N}}(\mathrm{x})$, is defined as the number of stones transported per wave. Later on (Alikhani 1996) investigated not only the influence of wave obliquity on the longshore transport at the trunk both during and after reshaping, but also the initiation of longshore transport. Additionally also the influence of storm duration and of short crested directional waves were studied from test results at AAU.

According to this research stones will not move in longitudinal direction as long as the longshore component of the energy flux is not large enough to move them. This led to threshold values for both the reshaping phase and equilibrium phase. Furthermore Eq. 12 for transport after reshaping was modified by including the longshore component of the incident wave energy:

$$
S_{N}=0.8 \cdot 10^{-6} \sqrt{\cos \psi}\left(H_{0} T_{0 p} \sqrt{\sin 2 \psi}-75\right)^{2}
$$

Accordingly this formula together with the also derived threshold values give a maximum transport for $\psi=45^{\circ}$ with decreasing tendency for larger and smaller angles and zero transport for head-on waves and waves parallel to the structure.

To describe the wave attack intensity under the assumption that onshore wave energy flux is conserved (Tomasicchio et al. 1994) defined a modified stability number:

$$
N_{s}^{* *}=\frac{H_{k}}{C_{k} \Delta D_{n 50}}\left(\frac{s_{m o}}{s_{m k}}\right)^{-1 / 5}(\cos \psi)^{2 / 5} \simeq \frac{0.89 H_{k b}}{C_{k} \Delta D_{n 50}}
$$

In this formula $\mathrm{H}_{\mathrm{kb}}$ is defined as the characteristic breaking wave height, $\mathrm{s}_{\mathrm{m} 0}$ is the mean wave steepness in deep water, based on a mean wave period, and $\mathrm{s}_{\mathrm{mk}}=0.03$ is assumed as reference wave steepness. For $\mathrm{s}_{\mathrm{m} 0}=\mathrm{s}_{\mathrm{mk}}$ and head-on waves $\mathrm{N}_{\mathrm{s}}^{* *}$ equals $\mathrm{H}_{0}$, the stability number. Besides the derivation of modified stability number also a model was proposed relating longshore transport to stone mobility on the already reshaped profile. In this model displacement of stones takes place during the up- and down-rush in the direction of incident and reflected waves. In (Tomasicchio et al. 2007) this model was revised for an arbitrary number of waves, $\mathrm{N}$ :

$$
S_{N}=\frac{l_{d}}{D_{n 50}} \frac{N_{o d}}{N} \sin \psi_{k b}
$$

During a small time interval, a particle will pass through a control section if and only if it is removed from the upstream area of extension equal to the displacement length, $1_{\mathrm{d}}$. The number of stones removed from this area after $\mathrm{N}$ waves, per one stone diameter wide strip, is then $\mathrm{N}_{\mathrm{od}}$ and $\psi_{\mathrm{kb}}$ is the characteristic wave obliquity at breaking point. This transport can also be given in terms of a volume transport, $\mathrm{S}_{\mathrm{V}}$ :

$$
S_{V}\left[\mathrm{~cm}^{3} / \mathrm{s}\right]=\frac{S_{N} D_{n 50}^{3}}{(1-n) T_{m}}
$$

In this relation $\mathrm{n}$ is the porosity defined as the fraction of voids, $\mathrm{V}_{\mathrm{v}}$, over the total volume, $\mathrm{V}_{\mathrm{T}}$. In none of the abovementioned formulas any relation regarding the longshore transport and stone grading is described. 


\section{D PHYSICAL MODEL TESTS}

To investigate the influence of a wide stone grading on both the two-dimensional deformation and longshore transport further in more detail a new test program was set up. In the second half of 2009 a series of physical model tests were carried out in the wave basin at Delft University of Technology. In total 12 tests were executed in which two different gradings were tested: a narrow grading, $\mathrm{f}_{\mathrm{g}}=1.3$, and a wide grading, $\mathrm{f}_{\mathrm{g}}=6$. Other parameters varied were the wave spectrum, with values for $\mathrm{H}_{\mathrm{m} 0}$ of $0.08 \mathrm{~m}$ and $0.10 \mathrm{~m}$, and the angle of wave attack with values for $\psi$ of $0^{\circ}, 30^{\circ}$ and $45^{\circ}$. To keep the different tests apart every test was given a name composed of the values of the varied parameters. In this name the ' $N$ ' stands for the narrow grading of 1.3 , while ' $\mathrm{W}$ ' represents the wide grading of 6 . The significant wave height is indicated in centimeters. Table 1 shows the test schedule as executed.

\begin{tabular}{|c|c|c|c|c|c|c|c|c|c|c|c|}
\hline \multicolumn{6}{|c|}{$f_{g}=1.3$} & \multicolumn{6}{|c|}{$f_{g}=6$} \\
\hline & & & & & & & & & & & \\
\hline $0.08 \mathrm{~m}$ & $0.10 \mathrm{~m}$ & $0.08 \mathrm{~m}$ & $0.10 \mathrm{~m}$ & $0.08 \mathrm{~m}$ & $0.10 \mathrm{~m}$ & $0.08 \mathrm{~m}$ & $0.10 \mathrm{~m}$ & $0.08 \mathrm{~m}$ & $0.10 \mathrm{~m}$ & $0.08 \mathrm{~m}$ & $0.10 \mathrm{~m}$ \\
\hline $\mathrm{N}-0-8$ & $\mathrm{~N}-0-10$ & $\mathrm{~N}-30-8$ & $\mathrm{~N}-30-10$ & $\mathrm{~N}-45-8$ & $\mathrm{~N}-45-10$ & W-0-8 & W-0-10 & W-30-8 & W-30-10 & W-45-8 & W-45-10 \\
\hline
\end{tabular}

The breakwater model had a geometrical scale of 1:20 and was divided in a test section consisting of loose stones and a fixed part. The base of the model had a length of $6.7 \mathrm{~m}$ and a width of $2.2 \mathrm{~m}$. Together with a slope of $2: 3$ and a height of $0.55 \mathrm{~m}$ this led to a crest width of $0.55 \mathrm{~m}$. The radiuses of respectively the crest and the base of the roundhead were $0.275 \mathrm{~m}$ and $1.1 \mathrm{~m}$. In the following drawings, Fig. 2 to 4 , the test section is represented by the hatched part. Two strips of $0.10 \mathrm{~m}$ filled with dyed stones were added to accommodate for visual measurements concerning the longshore transport.

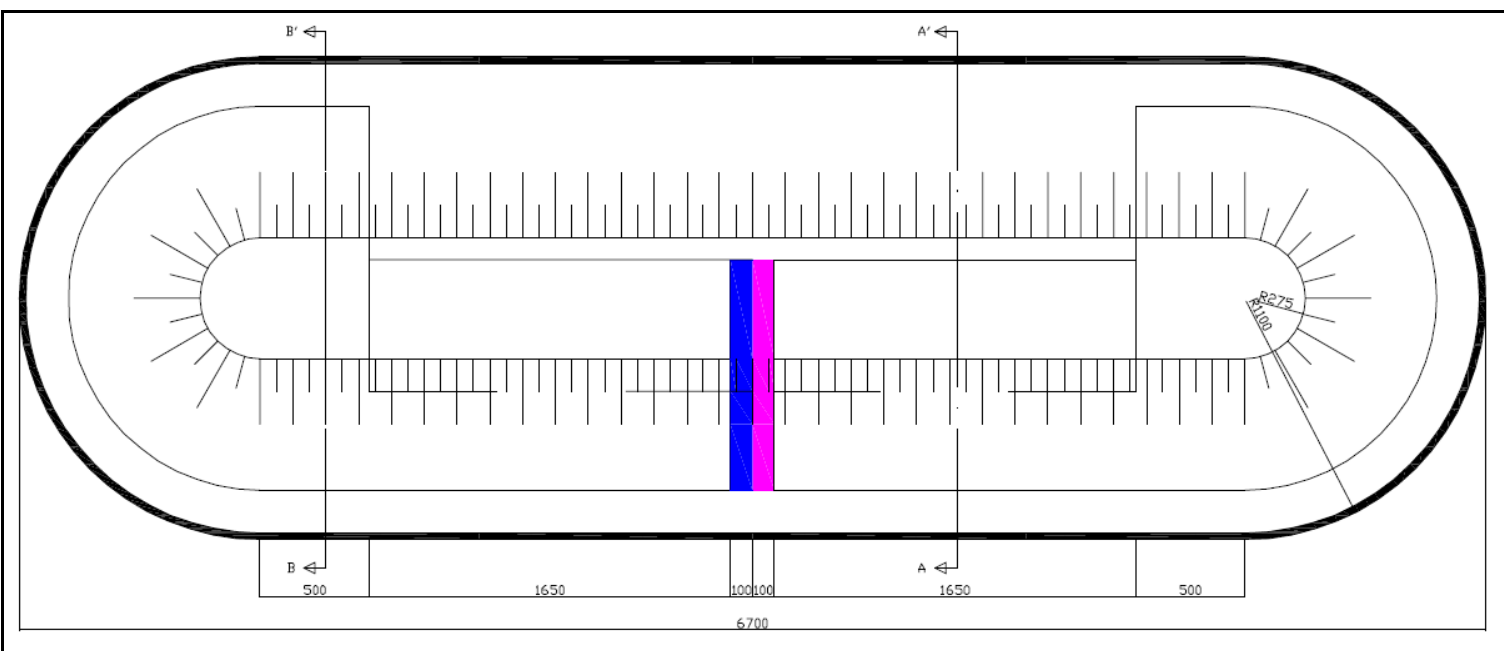

Figure 2: Topview breakwater model

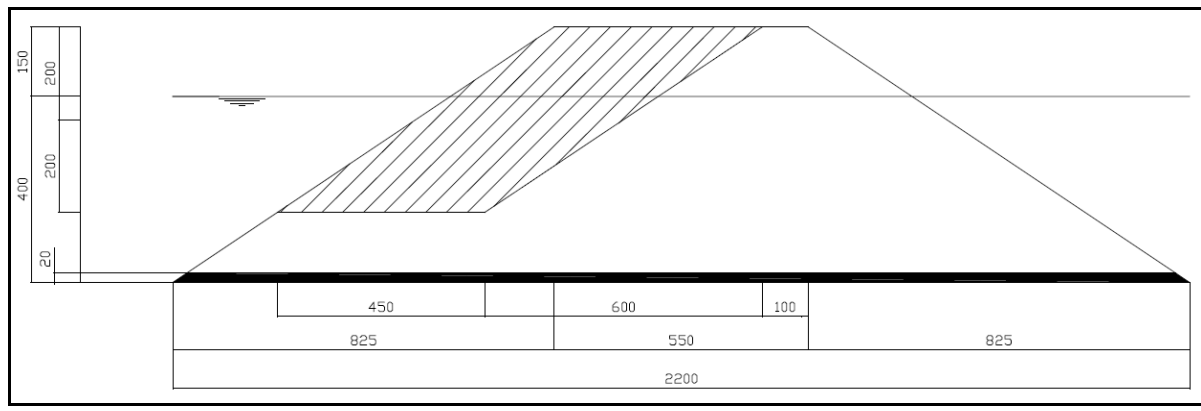

Figure 3: Cross-section A-A 


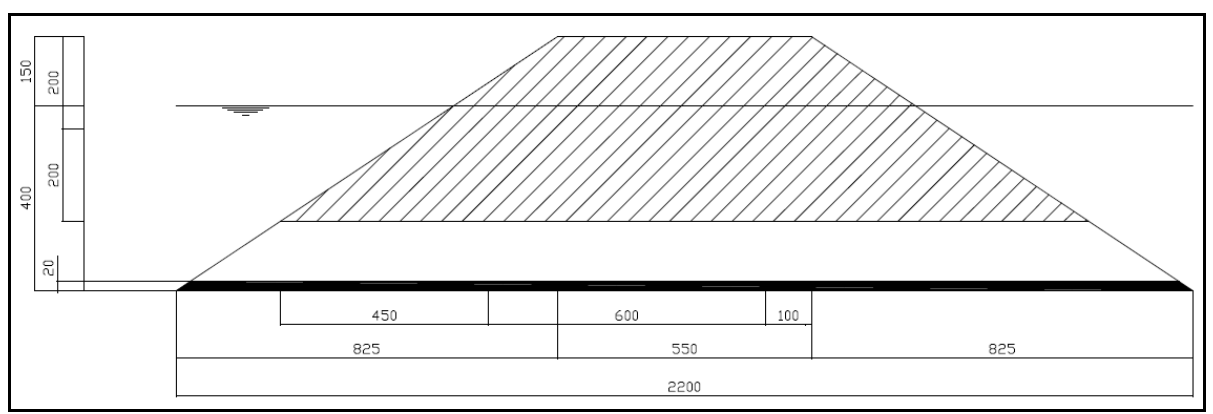

Figure 4: Cross-section B-B'

In order to compose the narrow and wide gradings, while keeping the nominal diameter the same at $D_{n 50}=12.1 \mathrm{~mm}$, five different stone fractions were used. The stone samples were mixed in such a way that the mixtures were representative of respectively armour stone material $\left(f_{g}=1.3\right)$ and quarry run $\left(f_{g}\right.$ $=6$ ). Table 2 shows the characteristics of both mixtures and Fig. 5 shows final result on the breakwater model itself.

\begin{tabular}{|c|c|c|c|c|}
\hline \multicolumn{5}{|c|}{ Table 2. Nominal diameters and weights of narrow and wide grading } \\
\cline { 1 - 4 } Grading & $f_{g}=1.3$ & $f_{g}=6$ & $f_{g}=6$ (scale factor 20) & $W(k g)\left(\rho_{s} D_{n}{ }^{3}\right)$ \\
\cline { 1 - 3 }$D_{n 15}(m m)$ & 10.4 & 5.2 & 103.7 & 3.0 \\
\cline { 1 - 1 }$D_{n 50}(m m)$ & 12.1 & 12.1 & 241.6 & 37.6 \\
\cline { 1 - 1 }$D_{n 85}(m m)$ & 13.8 & 31.1 & 621.7 & 640.7 \\
\cline { 1 - 3 }$D_{n 85} / D_{n 15}$ & 1.33 & 6.00 & 6.00 & \\
\hline
\end{tabular}

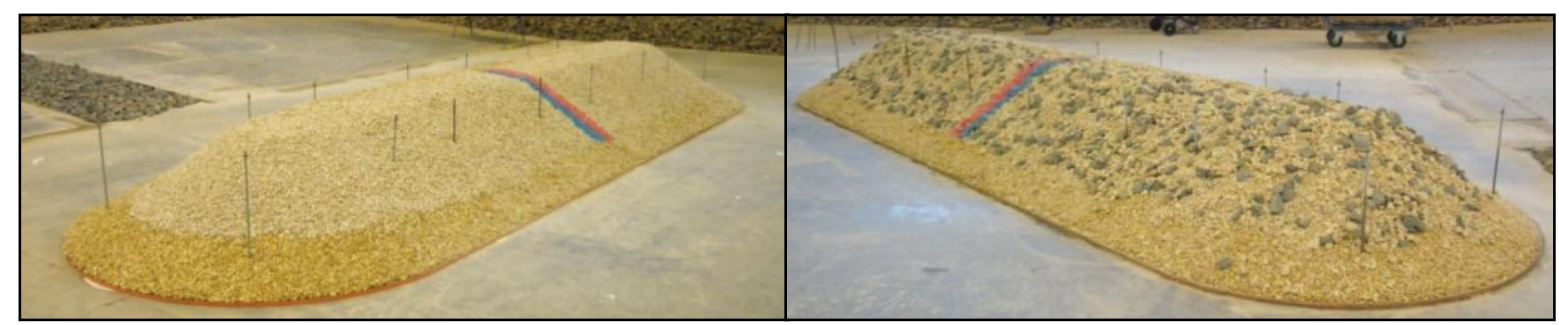

Figure 5: Final results of the mixtures on the breakwater model

For the wave load itself two different JONSWAP spectra were generated, in which the significant wave height was varied, $\mathrm{H}_{\mathrm{m} 0}=0.08 \mathrm{~m}$ and $0.10 \mathrm{~m}$, while the fictitious peak wave steepness $\mathrm{s}_{0 \mathrm{p}}$ was kept constant at 0.030 . The total durations of the tests were varied for the two different spectra so that the number of waves was the same, approximately 3500 waves. In order to check the actual occurring wave spectra during the tests together with the directional spectrum of the waves, five resistive wave gauges were place in a spatial distribution. The different angles of wave attack were obtained by rotating the model itself. The final test set-up is visualized in Fig. 6. 


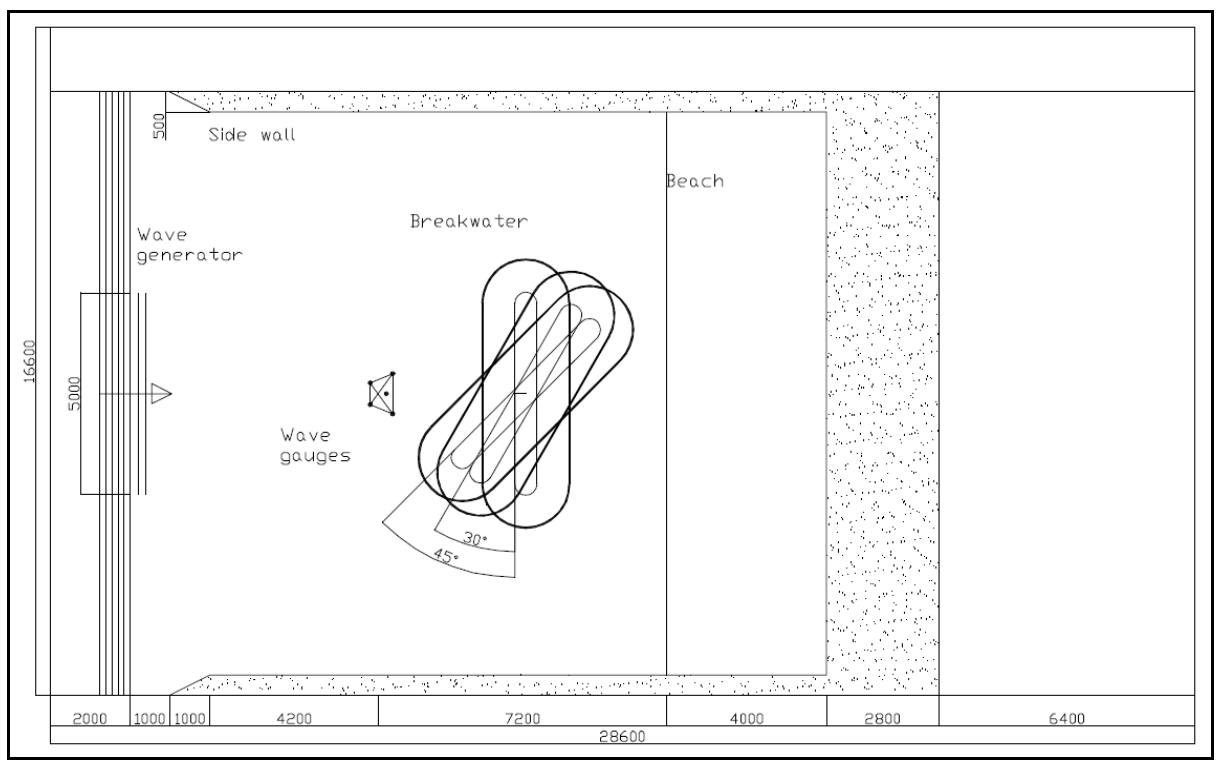

Figure 6: Rotation of breakwater model inside the wave basin

\section{Measurements}

Profile measurements were done both prior to and after the tests by means of laser profiling. The measurements were taken according to the following cross-sectional plan, displayed in Fig. 7:

- At the roundhead every $15^{\circ}$

- At the trunk every $0.5 \mathrm{~m}$

- Around the colour beams every $0.1 \mathrm{~m}$

Due to extensive damage additional measurements were sometimes necessary at the roundhead to provide for extra information.

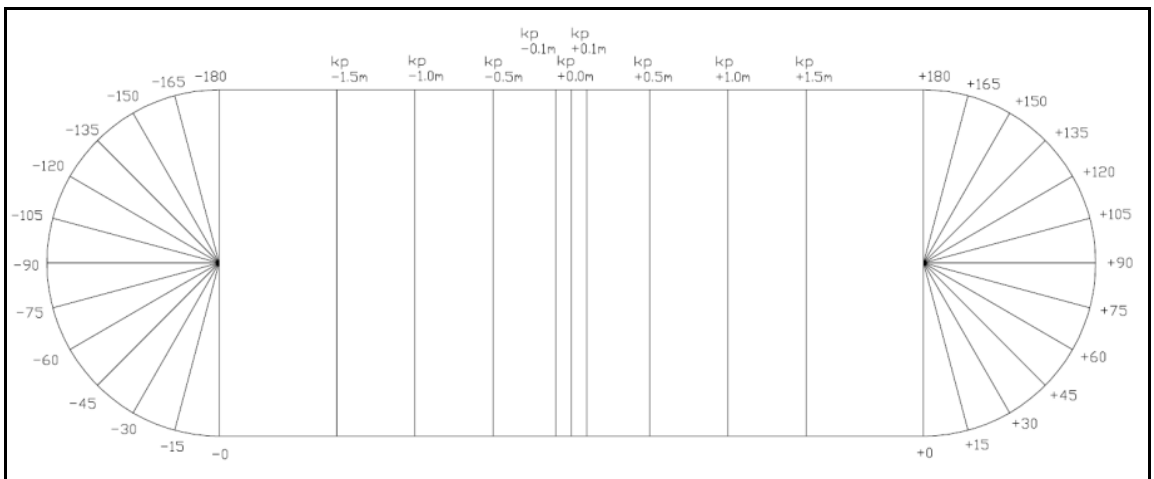

Figure 7: Cross-sectional measuring plan

Registering the longshore transport turned out to be rather difficult. Firstly the longshore transport proved to be larger than expected. Secondly following the stones was complicated by the twodimensional deformation which covered the transported stones as quickly as the stones itself were released. Therefore the longitudinal transport was determined by measuring the stone displacements of the stones originating from the two colour bands in the middle of the trunk. Accordingly the left half of the breakwater was divided in six sections leading to a total of 11 data points:

-One strip of $0.1 \mathrm{~m}$ width (blue colour beam) which served as an extra data point for the transport of pink stones

- Four $0.5 \mathrm{~m}$ wide sections on the trunk

- Last part of the trunk together with the left roundhead, which served as 2 data points for the rest factor

The number of transported stones originating from the two colour bands were then measured per colour per section. 


\section{RESULTS}

\section{Two-dimensional deformation}

Through linear interpolation the profile measurements were processed into three-dimensional models which display the profile deformation clearly for each test. This process is shown in Fig. 8 and 9. By subtracting the initial profile from the deformed profile an erosion model was created in which areas of erosion and accretion became visible, see Fig. 10.

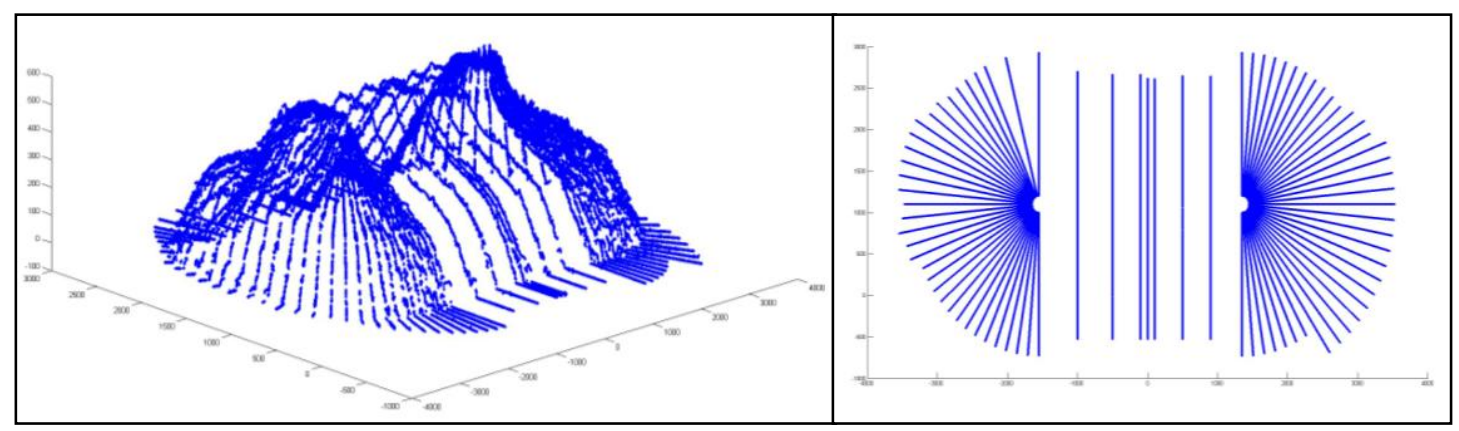

Figure 8: Converting two-dimensional profile measurements in a 3D-model

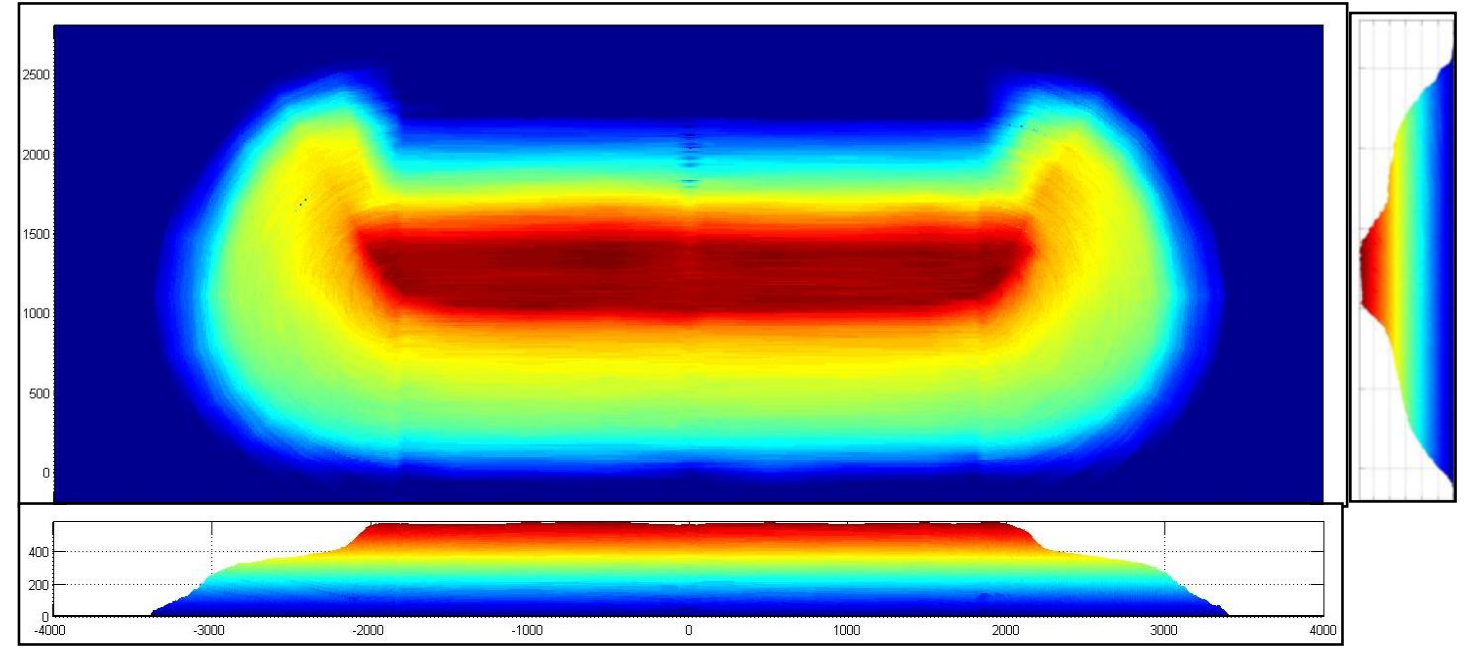

Figure 9: Three-dimensional model after test N-0-10

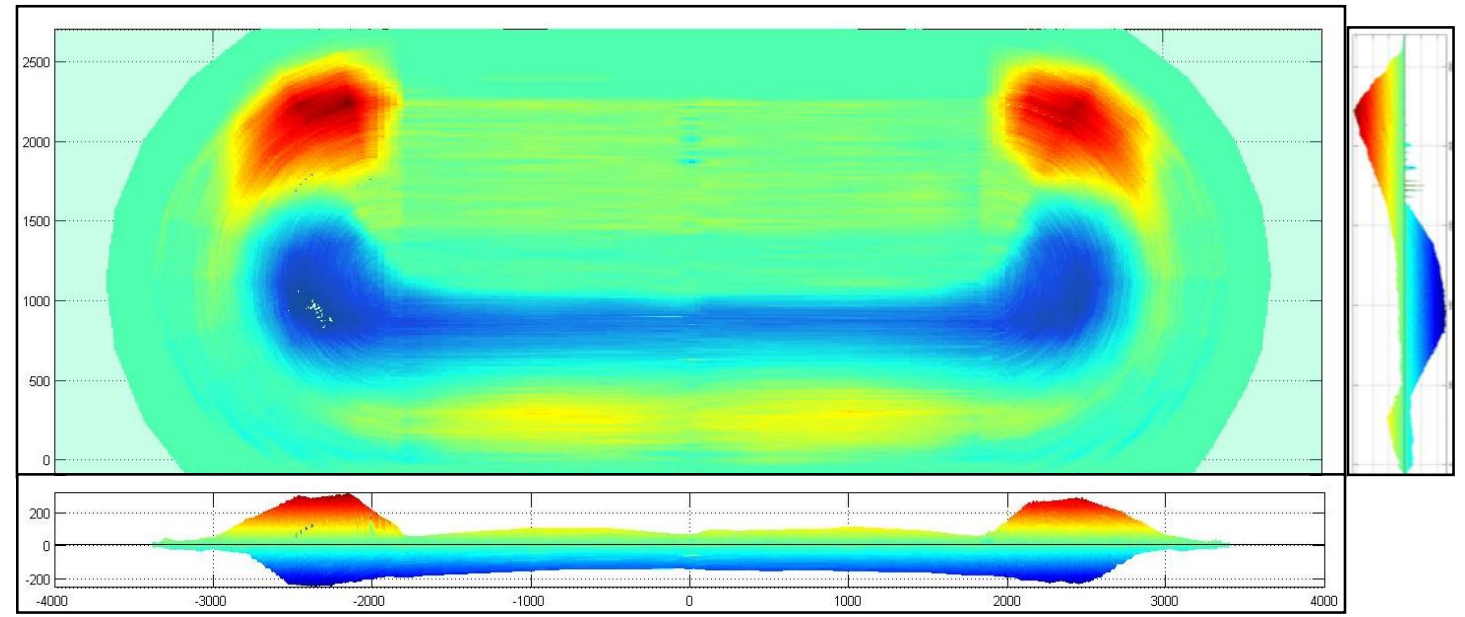

Figure 10: Erosion model after test $\mathrm{N}-0-10$

For the two-dimensional deformation the test results were compared to currently available formulas. Observed deformation parameters were compared with relations derived by Van der Meer and Veldman and Merli, while predictions of formulas of Hall \& Kao, Tørum and Merli were compared to the actual recession lengths, Rec. 


\section{Crest length ' $\boldsymbol{l}_{\mathrm{c}}$ '}

While the angle of wave attack did not appear to have an influence on the crest length, $1_{c}$, the grading clearly did, see left graph Fig. 11. Namely a wider grading resulted in a longer crest length. The test data therefore produced a good fit with Eq. 8, which also describes the effect of grading. Only for values of $f_{g}=1.3$, which fall outside the range of grading tested by Merli, the values for $l_{c}$ were underestimated.

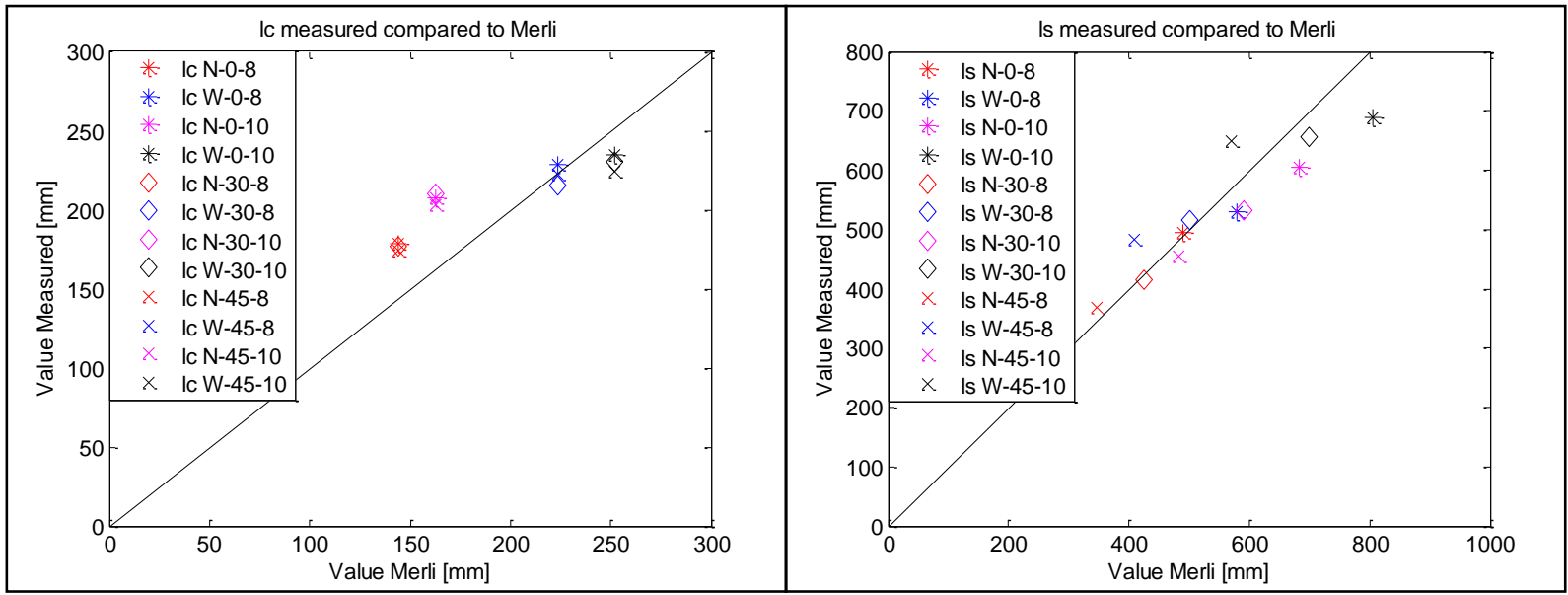

Figure 11: Comparison measured ' $\mathrm{I}_{\mathrm{c}}$ ' and 'I $\mathrm{s}$ ' with Eq. 8 and 9 of (Merli 2009)

\section{Step length ' $\mathrm{l}_{\mathrm{s}}$ '}

Also for the step length, $1_{\mathrm{s}}$, the effect of grading was evident as is shown by the right graph of Fig. 11; longer step lengths were observed for wider gradings. Accordingly Eq. 9 derived by Merli gave the best description. The effect of wave obliquity however appeared ambiguous. While for narrow grading during the tests this effect neared the reduction factor, $\cos \psi$, for wide grading hardly any difference was found between the different angles of wave attack. Apparently the reduction factor is grading dependent.

\section{Crest height ' $h_{\mathbf{c}}$ '}

Whereas Eq. 3 of Van der Meer shows a clear distinction for different wave loads and angles of wave attack, see left graph Fig. 12, no distinction was found in the values of the current test data. In fact all values found were equal to the initial freeboard of the breakwater model. Consequently all values for $\mathrm{h}_{\mathrm{c}}$ were underestimated. The freeboard of the current breakwater model however was relatively high, while the relation was derived for berm breakwaters with the berm around still water level. It is assumed that the part of the outer slope above the initial deformation collapsed due to instability, partly because of the relatively steep slope. This process then continued, so that eventually the same value for $\mathrm{h}_{\mathrm{c}}$ was acquired as the initial freeboard.
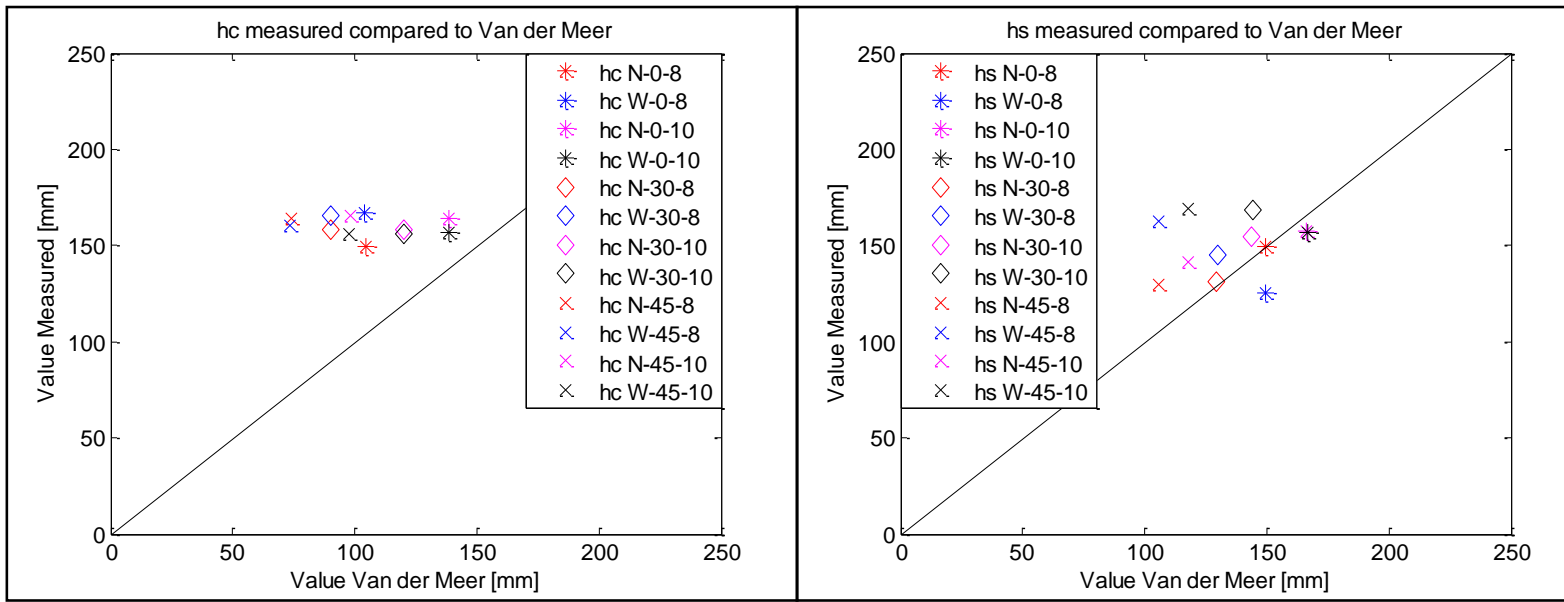

Figure 12: Comparison measured ' $h_{c}$ ' and ' $h{ }_{s}$ ' with Eq. 3 and 5 of (Van der Meer 1992) 


\section{Step height ' $h$ '}

For the step height $h_{s}$, displayed in the right graph of Fig. 12, a more or less similar observation was done as for $1_{\mathrm{s}}$ during tests with wide grading: no effect was found regarding the angle of wave attack. However, now this observation was also done for tests with narrow grading. Apparently the effect of wave obliquity is not adequately described by the reduction factor, $\cos \psi$. Consequently for $h_{s}$ it can even be suggested to omit the reduction factor entirely.

Regarding the effect of stone grading, a different relation was found: $h_{s}$ increased for wider grading. This effect however seemed influenced by the angle of wave attack. The larger the angle of wave attack, the larger this increase from narrow to wide grading appeared to be.

\section{Slope below crest ' $\boldsymbol{~}_{3}$ '}

As can be seen from the left graph of Fig. 13, Eq. 10 had the tendency to underestimate the values for $\theta_{3}$ observed from the tests. As the test results were directly related to the values of $h_{c}$, which showed a clear underestimation, this was expected. Regarding the different parameters tested both a higher wave load and a wider grading led to a lower value of $\theta_{3}$. The degree of decrease however differed slightly from the relation given. While the decrease of $\theta_{3}$ due to a wider grading tended to lag behind, the decrease of $\theta_{3}$ due to a higher wave load was actually more pronounced. No one-sided relation was found for the effect of wave obliquity.

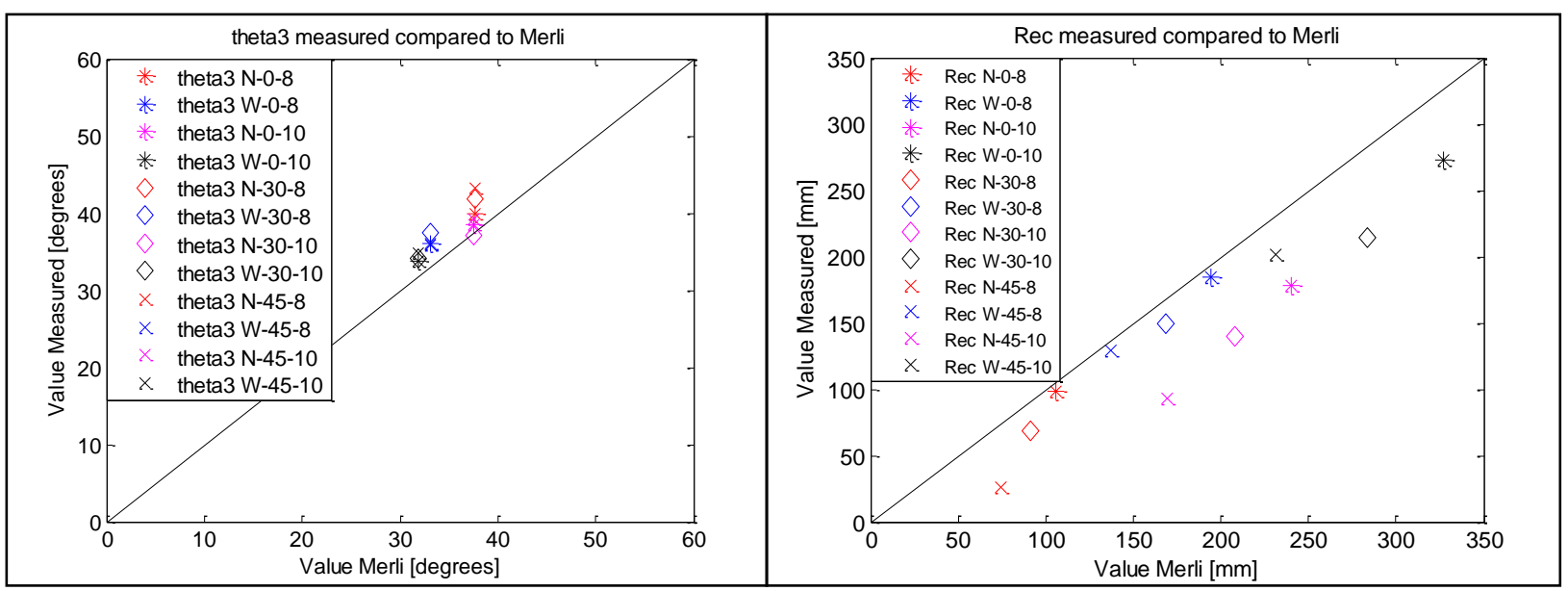

Figure 13: Comparison measured ' $\theta_{3}$ ' and 'Rec' with Eq. 10 and 11 of (Merli 2009)

\section{Crest recession 'Rec'}

Both a more severe wave load and wider grading resulted in a larger recession length, Rec. For the values of $\mathrm{H}_{0} \mathrm{~T}_{0}$ and $\mathrm{f}_{\mathrm{g}}$ used, the influence of the wider grading was even larger than was the case by increasing the wave load. Regarding wave obliquity, a larger angle of wave attack led to a smaller value of Rec.

In the comparison with formulations derived by Tørum, Hall \& Kao and Merli, the best description was given by Eq. 11 of Merli, as is shown by the right graph of Fig. 13. Although all values were overestimated, again a result of the different relation observed for $h_{c}$, the linear trend described gave the best method of approach. Also here the narrow grading of 1.3 led to a larger overestimation thereby reinforcing the conclusion given for $l_{c}$; that this grading falls outside the range of this formula.

Another point of attention was the reduction factor, $\cos \psi$. Apart from the tests with wide grading and a wave obliquity of $45^{\circ}$, a general trend was visible for larger angles in which the overestimation became higher. So the reduction factor for Rec should show a faster reduction for increasing angles.

\section{Longshore transport}

After each test the stone displacement measurements yielded a total of 11 data points. By way of extrapolation additional data points were generated in the first $5 \mathrm{~cm}$ from the centre and beyond the roundhead. Subsequently for each test an exponential relation was derived between the amounts of stones found, originating from a $10 \mathrm{~cm}$ wide strip in the centre of the breakwater, and the distance from this centre of the breakwater.

Under the assumption of uniform transport at the trunk, data from this strip was then extrapolated to other $10 \mathrm{~cm}$ wide sections along the breakwater from which the total longshore transport could be determined through integration. The longitudinal transport is then defined as the total amount of stones that has passed the downstream border of the area of uniform transport after 3500 waves. Accordingly 
for every test the area of uniform transport was established. This method of determination is visualized in Fig. 14.

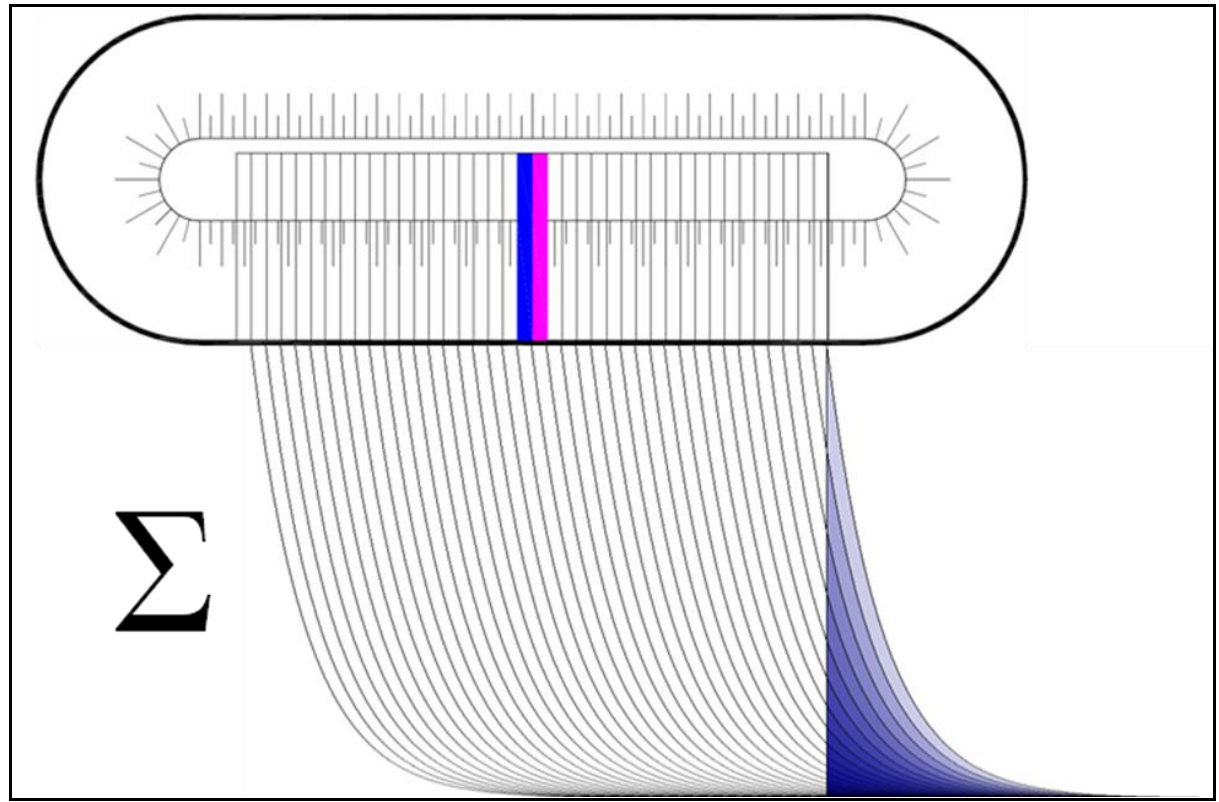

Figure 14: Determination of longshore transport from stone displacement graphs

Following the above-mentioned method the longshore transport rates were determined for every test with oblique waves. The results are displayed in Table 3.

\begin{tabular}{|c|c|c|c|c|c|c|c|c|}
\hline & $\mathrm{N}-30-8$ & $N-30-10$ & $\mathrm{~N}-45-8$ & $N-45-10$ & W-30-8 & W-30-10 & W-45-8 & W-45-10 \\
\hline $\begin{array}{c}\text { Transport } \\
\text { (stones/wave) }\end{array}$ & 0.445 & 1.235 & 0.196 & 1.061 & 0.520 & 7.161 & 1.933 & 5.705 \\
\hline
\end{tabular}
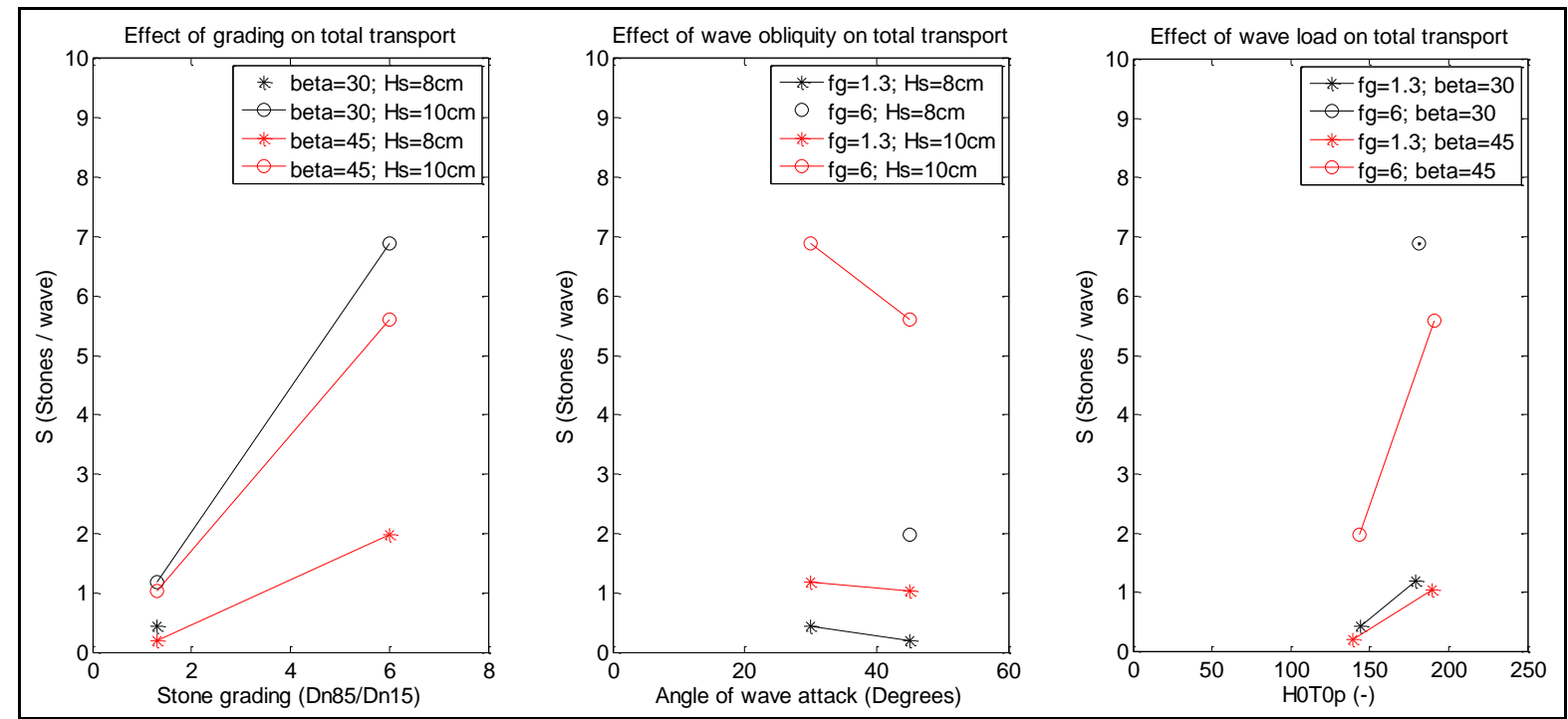

Figure 15: Influence of grading, wave obliquity and wave load on longshore transport

In Fig. 15 these transport rates are plotted against the parameters tested. From these graphs one data point was omitted as the displacement measurements of test W-30-8 did not lead to representative results. Aside from the data point of test W-30-8 consistent tendencies could be found regarding each varying parameter. Clearly visible was the increasing trend for increasing grading and wave parameter, $\mathrm{H}_{0} \mathrm{~T}_{0}$. In both cases this resulted in a much larger spreading. Furthermore the increase in longshore 
transport, due to an increase in grading, seemed to be stronger for the more severe wave load. The same held true for increasing $\mathrm{H}_{0} \mathrm{~T}_{0}$ as the rate of increase appeared to be larger for the wider grading.

In the second graph a decreasing trend between $30^{\circ}$ and $45^{\circ}$ is evident, which is in accordance with (Van der Meer and Veldman 1992) and (Tomasicchio et al. 2007), but not with the transport formula of (Alikhani 1996). Although the longshore current generated by oblique waves was larger, the impact and therefore load on the structure was less leading to a reduction in longshore stone transport. However, the rate of decrease for the tests with narrow grading was less pronounced than for wide grading and severe wave load.

\section{Comparison with currently available formulas}

In total three formulas were used in the comparison with the test data. Although constantly an overestimation was found in the order of magnitude 8 , data concerning the tests with narrow grading produced a relatively nice fit with other test results when Eq. 15 of (Tomasicchio et al. 2007) was used, see left graph of Fig. 16. This formula describes the decreasing trend between $45^{\circ}$ and $30^{\circ}$ well, but is rather laborious in the computation as multiple parameters have to be defined.

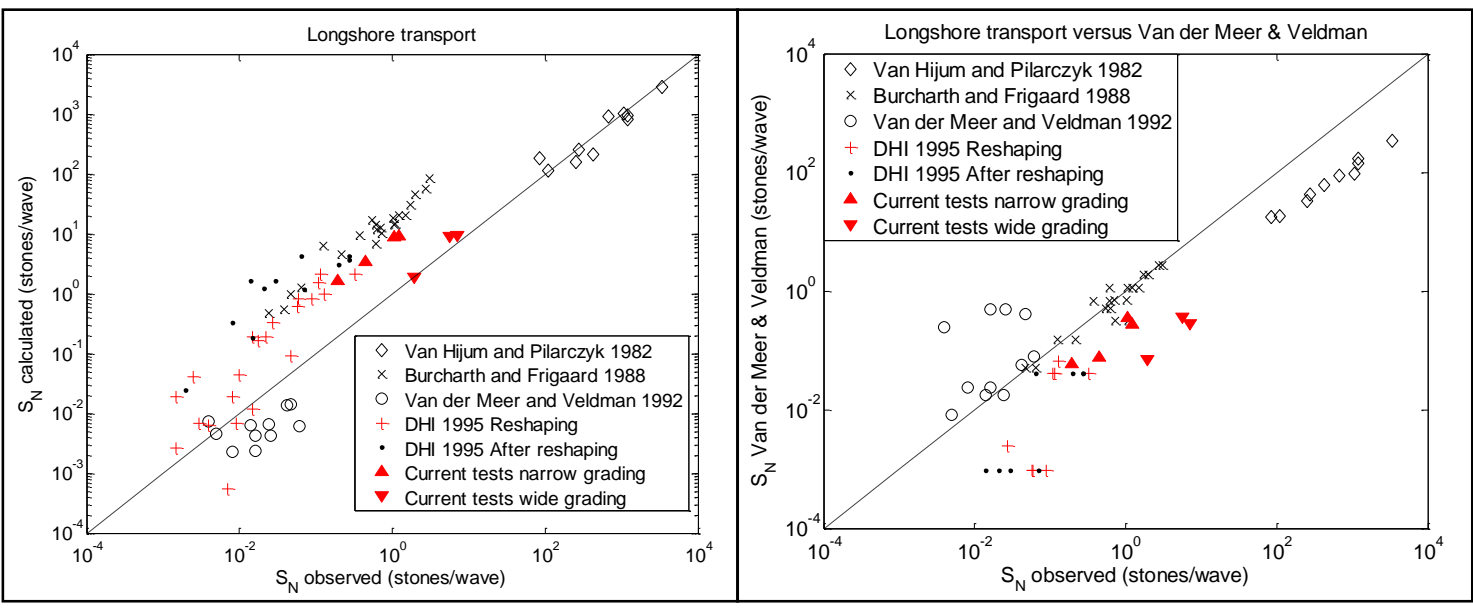

Figure 16: Comparison of test results with Eq. 15 of (Tomasicchio et al. 2007) and Eq. 12 of (Van der Meer and Veldman 1992)

Eq. 12 was derived by (Van der Meer and Veldman 1992) for already deformed profiles under the same assumption as mentioned above. Nevertheless no influence of wave obliquity was included in the relation. In the comparison with all previous test results, displayed by the right graph of Fig. 16, a relatively nice fit was produced. Nonetheless the effect of neglecting wave obliquity was still visible, especially for a wave obliquity of $50^{\circ}$. At the same time the data of tests during reshaping were consequently underestimated as the values of $\mathrm{H}_{0} \mathrm{~T}_{0}$ were close to the threshold value.

Unlike Eq. 12 the angle of wave attack is included in Eq. 13, which was formulated by (Alikhani 1996). This formula however gives a different relation for the angle of wave attack which is in contrast to the relation found from the test results: increasing longshore transport for increasing obliquity with a maximum for $45^{\circ}$. In the comparison with previous test results a very large underestimation was found for most values. This leads to the conclusion that in the derivation of Eq. 13 probably some errors were made. By multiplying the coefficient with a factor 100 however, shown in Fig. 17, a rather nice fit was found, especially for the current test results with narrow grading. This new coefficient, $8 * 10^{-5}$, is then also in the same order of magnitude as previous coefficients derived by (Van der Meer and Veldman 1992) and leads to the following renewed version of Eq. 13:

$$
S_{N}=8 \cdot 10^{-5} \sqrt{\cos \psi}\left(H_{0} T_{0 p} \sqrt{\sin 2 \psi}-75\right)^{2}
$$




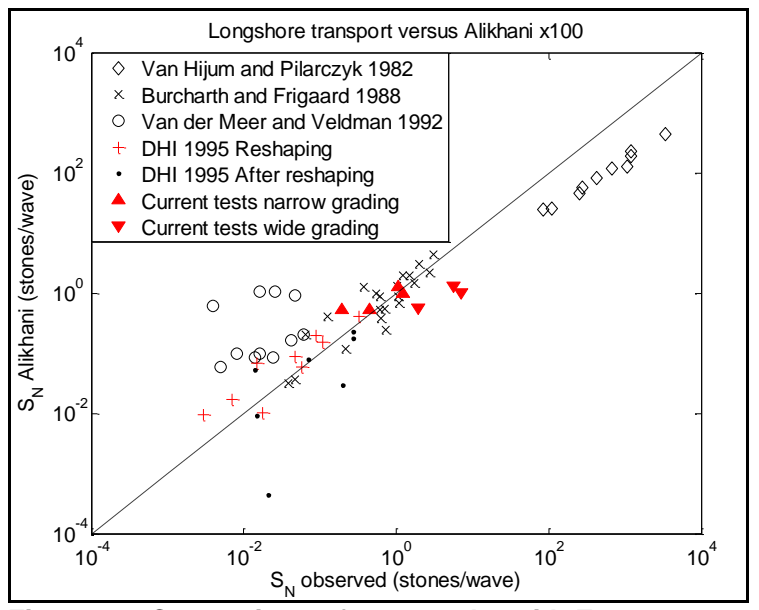

Figure 17: Comparison of test results with Eq. 17

\section{Relation with modified stability number}

When the observed values for the longshore transport were plotted against the modified stability number, described by Eq. 14, the data of the current tests with narrow grading were nicely in line with the other datasets of berm breakwaters. However, data of tests with wide grading did not fit in. This is shown in the left graph of Fig.18 in which a distinction is made in three different regions. The first region, $2<\mathrm{N}_{\mathrm{s}}^{* * * *}<6$, refers to berm breakwaters and the third to gravel beaches, $9<\mathrm{N}_{\mathrm{s}}^{* * *}<24$. The second region forms a transition region and can be referred to as rock and cobble beaches, $6<\mathrm{N}_{\mathrm{s}}{ }^{* * *}<9$. No test data is yet available for this area.

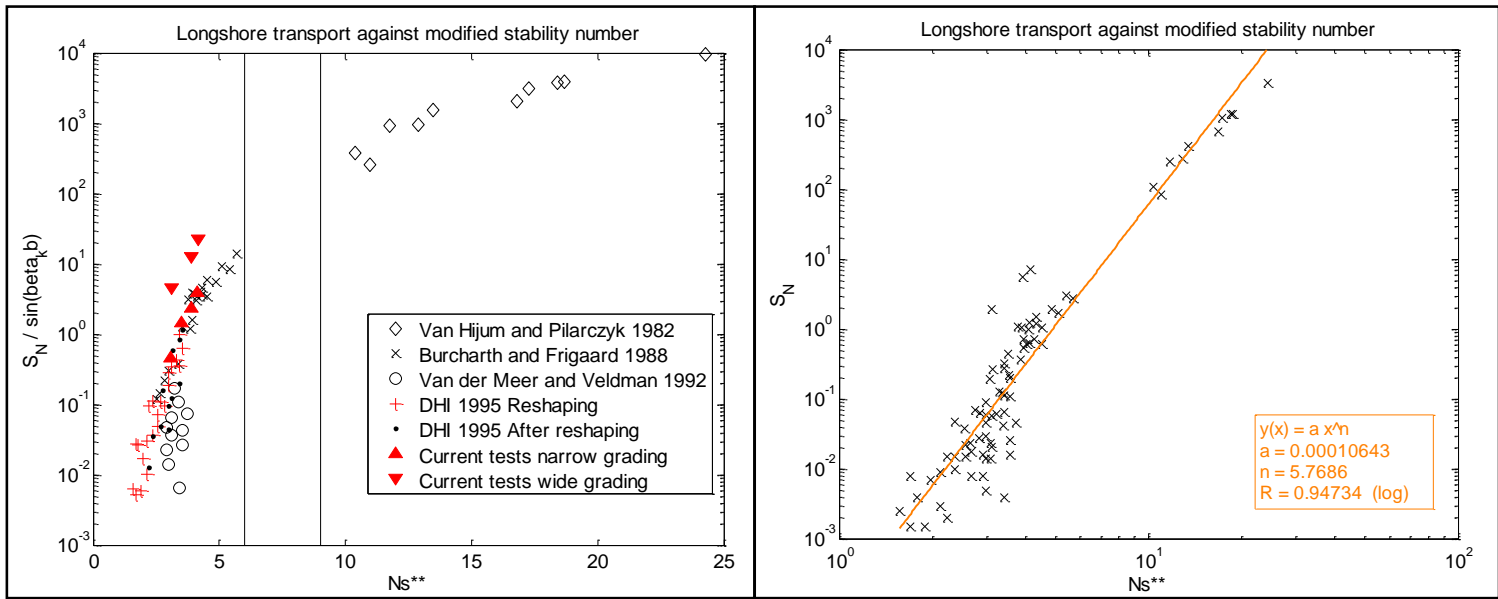

Figure 18: Longshore transport against modified stability number $\mathbf{N}_{s}$

In right graph of Fig.18 the same graph is plotted again, now with a double logarithmic scale. By means of curve fitting it was possible to draw a straight line through the data points. In this way a power function was derived linking the longshore transport rate to the modified stability number:

$$
S_{N}=10.64 \cdot 10^{-5}\left(N_{s}^{* *}\right)^{5.77}
$$

\section{Volume transport}

Whereas the transport rate in stones/wave was used to describe the longshore transport for the narrow grading with acceptable results, a rather distorted image was produced by the computation of the same rate for wide to very wide grading. This distortion became better visible when the transport rate was converted into a volume transport rate using Eq. 16. Namely the increase in the volume transport from narrow to wide grading was not proportional to the longshore stone transport rate as not all fractions were transported evenly. While mostly the finer fractions determined the total longshore transport rate in stones/wave their contribution to the volume transport was far less. Accordingly a relatively large contribution was given by the coarser fractions. 
Except for the middle fractions however, no link was found between the contribution to the volume transport and distribution of the fractions inside the grading. The relatively large contributions by the finest and coarsest fractions were therefore attributed to either the higher mobility of the finest stones, even after reshaping, or the greater instability of the largest stones preceding deformation.

While the increase of the stone transport rate for the two gradings used varied between a factor 5 and 9 , a factor 2 was found for the corresponding increase of the total volume transport rate. Accordingly when the damage due to longshore transport needs to be determined, the longshore volume transport is preferred above the stone transport.

Conceptual model stone transport

By means of visual observations a conceptual model was developed for the reshaping phase as well as after reshaping describing the stone movements in both transverse and longitudinal direction. As no quantitatively data of the outer profile and longshore stone displacements were obtained during the tests, it was not possible determine the point in time on which the equilibrium profile was reached. Nevertheless, some distinctions between both phases were clearly visible.

During the reshaping phase deformation was dominated by stones rolling down the slope due to instability created by wave attack and gravity. Because of this dominant transverse component, stones transported in longitudinal direction due to oblique wave attack were quickly overwhelmed. While the actual rate of the longshore transport was high the displacement length was rather short.

After reaching an equilibrium profile the crest kept slowly crumbling off at the impact of the highest waves of the wave spectrum. Around the water line material continued to move in the direction of the incoming and reflected waves resulting in a transport along the breakwater in the case of oblique wave attack. Although the amount of stones transport was less than during the reshaping phase, the displacement length increased considerably. Stones kept being transported until the rear side of the breakwater was reached and further transport was prevented.

\section{Segregation}

During the tests with the wide grading a clear segregation of the mixture occurred in the transverse direction as well as the longitudinal direction. In the initial phase the coarsest fractions proved to be the most unstable thereby dominating the transport as result of gravity in mainly transverse direction. In this transport, which can better be described by large stones tumbling down the slope to a more stable position at the foot of the breakwater, other stone fractions were also dragged along. Later on after initial deformation, in which already an s-curve was visible, the coarsest fractions that came loose through deformation were deposited in a stable position on the gentle slope around still water level. Subsequently no further movement of the coarsest fractions was observed. While this transport was accompanied by only a minor displacement in longitudinal direction, the finer fractions were transported much further along the trunk. As even after reshaping no stable situation was reached for the finer fractions, stones kept moving along the waterline in the direction of the up- and down-rush of the waves. The finer the material, the further this transport proceeded until finally at the rear side of the roundhead further movement was prevented. Fig.19 shows the concept of stone movement for the different fractions as was observed and described above.

\section{CONCLUSION}

In order to obtain new information on both the two-dimensional deformation and the longshore transport at breakwater cores exposed to oblique wave attack new physical model tests were carried out. Data from these tests along with visual observations eventually led to a conceptual model describing stone movements in both transverse and longshore direction. With respect to the distance from origin, for each test an exponential relation was derived to describe the stone displacements. After determination of the area of uniform transport these exponential relations were used to calculate the total longshore transport by means of extrapolation and multiple integrations.

Subsequently all parameters found were compared to the formulas currently available for both processes. Regarding the deformation parameters the test results produced the best fit with the formulas derived in (Merli 2009). Still, on several occasions a deviant relation was found concerning the influence of wave obliquity. Additionally the formulas became less accurate for the narrow grading used in the tests, which fell outside the range tested by Merli. However, for the crest height of the deformed profile test results deviated completely from the available relation formulated by (Van der Meer 1992) as no influence was found whatsoever for all tested parameters. Here the deviation was contributed to a higher instability of the part above the initial deformation, partly due to the steepness of the slope. 


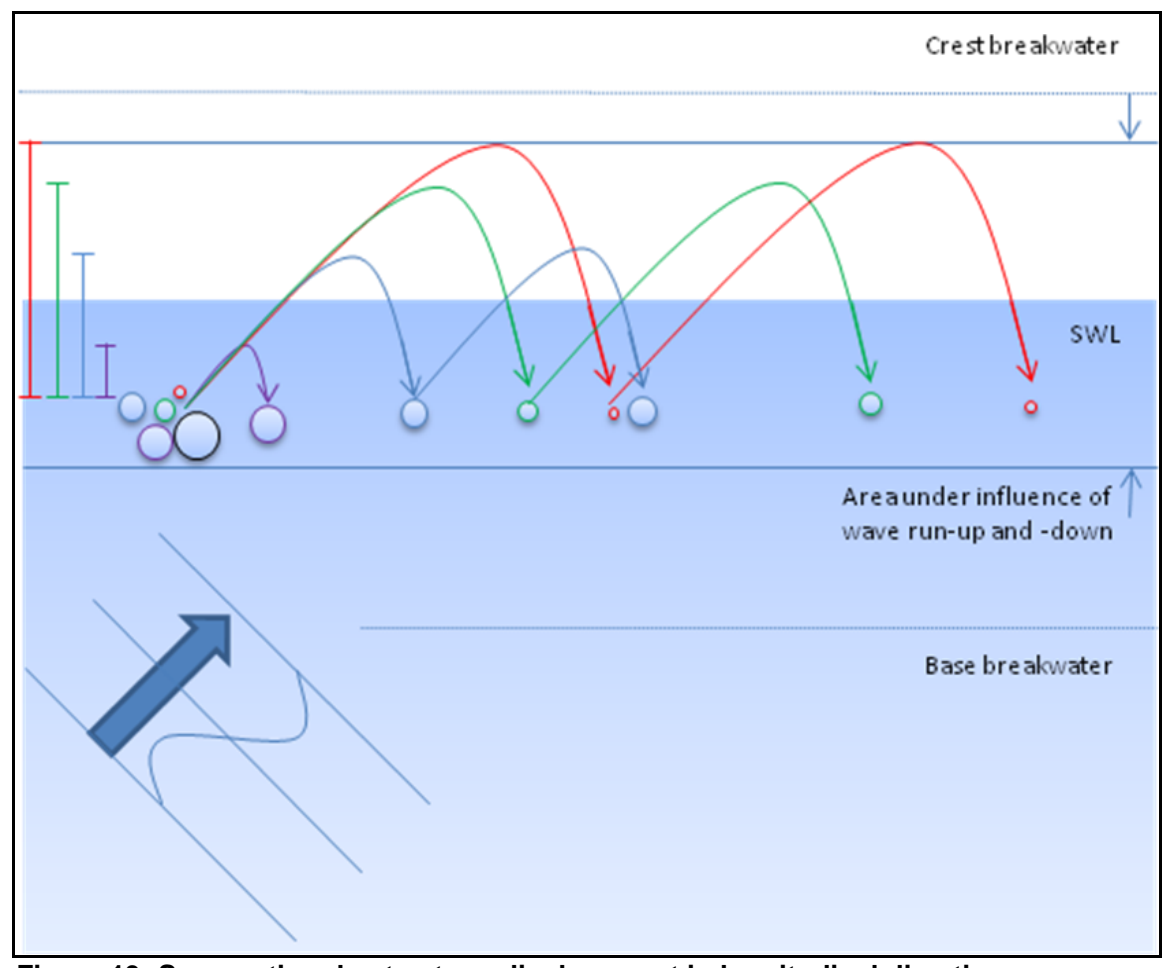

Figure 19: Segregation due to stone displacement in longitudinal direction

On the subject of the longshore transport clear trends were found describing the influence of the varying parameters. Both a higher wave load and wider grading led to an increase of the longshore transport. For the wider grading, however, this increase gave a rather distorted image, as not all fractions in the mixture were transported evenly. Due to segregation the coarsest fractions were mostly transported in the transverse direction while the finer fractions were transported further away in the longitudinal direction.

Alternatively, computation of the longshore volume transport proved to be more representative. While mostly the finer fractions determined the total longshore transport rate in stones/wave their contribution to the volume transport was far less. Accordingly a relatively large contribution was given by the coarser fractions. While the increase of the stone transport rate for the two gradings used varied between a factor 5 and 9 , a factor 2 was found for the corresponding increase of the total volume transport rate.

Regarding the effect of wave obliquity an increase in angle of wave attack of $30^{\circ}$ to $45^{\circ}$ was accompanied by a decrease in longshore transport; though this decrease was less than already available formulas indicated. However, despite the fact that it describes a completely different trend concerning this particular influence, the best fit was found after multiplying the relation derived by (Alikhani 1996) with a factor 100. By means of curve fitting also a new relation was found linking the modified stability number to the longshore transport. This relation can be described by Eq. 18:

$$
S_{N}=10.64 \cdot 10^{-5}\left(N_{s}^{* *}\right)^{5.77}
$$

\section{ACKNOWLEDGEMENTS}

The present study was initiated by and executed in cooperation with Van Oord. The accompanying test program was financed by Delft University of Technology who also provided the facilities to carry out the tests and gave the necessary technical support. 


\section{REFERENCES}

Alikhani, A., G.R. Tomasicchio and J. Juhl. 1996. Berm breakwater trunk exposed to oblique waves, Proceedings of 25th International Conference on Coastal Engineering, ASCE, 1528-1541.

Hall, K.R. and J.S. Kao. 1991. The influence of armour stone gradation on dynamically stable breakwaters, Coastal Engineering, 15.

Merli, D. 2009. Stability of wide-graded rubble mounds, UNESCO-IHE, Delft, MSc Thesis

Mulders, P.H.M. 2010. Breakwaters under construction exposed to oblique waves, Delft University of Technology, Delft, MSc Thesis

Pianc. 2003. State of the art of designing and construction berm breakwaters, MarCom; Report of WG 40, 2003, International Navigation Association, Brussels, Belgium, 2-87223-138-2

Tomasicchio, G.R., R. Archetti, F. D’Alessandro, P. Sloth. 2007. Long shore transport at berm breakwaters and gravel beaches, Proceedings of $5^{\text {th }}$ Coastal Structures International Conference CST07, Venice, Italy.

Tomasicchio, G.R., A. Lamberti and F. Guiducci. 1994. Stone movement on a reshaped profile, Proceedings of 24th International Conference on Coastal Engineering, ASCE, 1625-1640.

Van der Meer, J.W. 1988. Rock slopes and gravel beaches under wave attack, Delft University of Technology, Delft, PhD Thesis

Van der Meer, J.W. 1992. Stability of the seaward slope of berm breakwaters, Coastal Engineering, 16, 205-234.

Van der Meer, J.W. and J.J. Veldman. 1992. Singular points at berm breakwaters: scale effects, rear, roundhead and longshore transport, Coastal Engineering, 17, 153-171. 